\title{
Professoras dos anos iniciais da educação básica: aproximações e afastamentos em relação à Matemática
}

\author{
Teachers in the early years of basic education: \\ approaches and detachments towards Mathematics
}

Maestras de educación básica: acercamientos y desviaciones de las Matemáticas

\author{
ANDRÉA SILVA GINO* \\ MARIA LAURA MAGALHÃES GOMES**
}

\begin{abstract}
RESUMO - Este artigo apresenta alguns resultados de uma pesquisa de doutorado norteada pela seguinte questão: Como os professores que ensinam Matemática no $2^{\mathrm{o}}$ ciclo de formação da Rede Municipal de Educação de Belo Horizonte que cursaram a especialização em Educação Matemática do Curso de Pós-Graduação Lato Sensu em Docência na Educação Básica - LASEB percebem e narram as contribuições do curso? As contribuições do curso foram investigadas em narrativas de dez professoras, recolhidas em entrevistas, com o uso da metodologia da história oral. O foco do artigo está em um dos aspectos mais evidenciados nas narrativas, a saber, as aproximações e afastamentos das docentes em relação à matemática. Embora reconheçam que o LASEB tenha trazido aportes para a sua formação, as professoras, ao avaliarem seus próprios conhecimentos, consideraram os resultados do curso frágeis no sentido de sustentar seu papel de ensinar matemática nos anos iniciais do ensino fundamental.
\end{abstract}

Palavras-chave - Formação continuada de professores. Educação matemática. História oral.

\begin{abstract}
This article presents some results of a doctoral research guided by the following question: how teachers who teach Mathematics in elementary school perceive and narrate the contributions of LASEB, a Postgraduate Program for Teaching in Basic Education? The contributions of the course were investigated in ten narratives collected in interviews with ten teachers conducted according to the methodology of oral history. The focus of the article is one of the most evident aspects in the narratives, namely the approaches and detachments of the teachers towards mathematics. While acknowledging the contributions LASEB has brought to their training, the teachers considered the results of the course are not strong enough to support their role of teaching mathematics in the early years of elementary school.
\end{abstract}

Keywords - Continuing education of teachers. Mathematics education. Oral history.

RESUMEN - En este artículo, se presentan algunos resultados de una investigación doctoral norteada por la siguiente cuestión: como los docentes que enseñan Matemática en el $2^{2}$ ciclo de formación de la Red Municipal de Educación de Belo Horizonte que han cursado el posgrado de especialización en Educación Matemática del Curso de Posgrado Lato Sensu en Docencia en la Educación Básica - LASEB perciben y narran los aportes del curso? Esos aportes fueron investigados en relatos de diez maestras, recogidos en entrevistas, con el uso de la metodología de la Historia Oral de por medio. El foco del artículo está en uno de los aspectos más evidenciados en los relatos: los acercamientos y alejamientos de las maestras respeto a la Matemática. Aunque reconozcan que el LASEB trajo aportes a su formación, las docentes, al evaluar sus propios conocimientos, consideraron los resultados del curso frágiles en lo concerniente a sostener su rol de enseñar Matemática en los años iniciales de la Enseñanza Fundamental.

Palabras clave - Educación continua de maestros. Educación matemática. Historia oral.

\footnotetext{
*Doutora em Educação pela Universidade Federal de Minas Gerais (Belo Horizonte, MG, Brasil) e professora na Universidade do Estado de Minas Gerais (Belo Horizonte, MG, Brasil). E-mail: <andreasgino@gmail.com>.

**Doutora em Educação pela Universidade Estadual de Campinas (Campinas, SP, Brasil) e professora na Universidade Federal de Minas Gerais (Belo Horizonte, MG, Brasil).E-mail: <mlauramgomes@gmail.com>.
} 


\section{INTRODUÇÃO: SOBRE A FORMAÇÃO DE PROFESSORES QUE ENSINAM MATEMÁTICA NOS ANOS INICIAIS DA ESCOLARIZAÇÃO}

A formação do professor que ensina Matemática nos anos iniciais da educação básica é um tema de presença recente nas pesquisas sobre a formação de professores de Matemática no Brasil. De fato, no balanço de pesquisas realizado por Fiorentini e colaboradores (2002), a análise de 112 teses e dissertações produzidas no período de 1978-2002 mostrou que um terço das produções "estuda, analisa e avalia programas de formação inicial (24) ou continuada (15) de professores" (p. 141). Os autores encontraram, entre esses trabalhos, raros estudos que exploraram a formação do professor para ensinar Matemática nos anos iniciais do ensino fundamental. Segundo eles,

o que fica evidente neste balanço é que a pergunta "como acontece a formação didático-matemática dos professores nos cursos superiores de pedagogia?" parece não ter atraído ainda o interesse dos pesquisadores em Educação Matemática (FIORENTINI et al., 2002, p. 156).

Entretanto, em momentos mais atuais, o interesse dos pesquisadores brasileiros parece ter sido mobilizado, pois diversos estudos, a exemplo de Curi (2008), Nacarato e Paiva (2008), Nacarato, Mengali e Passos (2009) e Nacarato (2010), vêm se voltando especificamente para o tema da formação de professores que ensinam Matemática nos anos iniciais da escolarização.

Esses estudos evidenciam problemas no currículo de Matemática proposto pelos cursos que formam professores para atuarem nos anos iniciais, em que são enfatizadas questões metodológicas do ensino em detrimento da dimensão dos conteúdos matemáticos. Todavia, no que concerne à formação de professores em geral, parece haver consenso de que os saberes docentes são apenas parcialmente constituídos dos conhecimentos específicos em relação ao conteúdo das disciplinas. Assim, em análise sobre as tendências e perspectivas das pesquisas sobre formação de professores que ensinam matemática, Nacarato e Paiva observam:

As pesquisas que tomam os saberes docentes como objeto de estudo já rompem com a concepção de que o bom professor é aquele que tem apenas o domínio dos conteúdos. Não significa, porém, negar a importância dos conteúdos, mas partir do pressuposto de que o saber docente vai além dessa única dimensão do conhecimento (NACARATO; PAIVA, 2008, p. 14).

Entre os professores que atuam no primeiro segmento do ensino fundamental em nosso país, é muito raro encontrar profissionais que tenham realizado estudos de graduação em matemática. Muito frequentemente, esses docentes, denominados professores polivalentes (NACARATO; MENGALI; PASSOS, 2009), têm habilitação para a docência de todos os conteúdos desse nível de ensino, inclusive a Matemática, adquirida em uma formação de nível médio, o antigo Curso de Habilitação ao Magistério, acrescida, em decorrência da legislação brasileira atual, de uma formação universitária predominantemente em Pedagogia ou Curso Normal Superior. Nacarato, Mengali e Passos (2009) sublinham que ambas essas formações contam com um espaço muito reduzido para a preparação quanto aos conhecimentos matemáticos dos docentes. Segundo elas, na formação continuada, o modo de abordar esses conhecimentos precisaria se fundamentar nas práticas pedagógicas desenvolvidas pelos professores. Nessa linha, e destacando que a docência nos anos iniciais da escolarização é exercida majoritariamente pelas mulheres, as autoras enfatizam que

Os projetos de formação continuada deveriam levar em consideração o saber que a professora traz de sua prática docente, ou seja, a prática docente precisa ser tomada como ponto de partida e de chegada da formação docente. Isso porque os diversos estudos apontam que o saber da experiência (ou saber experiencial) é o articulador dos diferentes saberes, que a professora possui em seu repertório de saberes (NACARATO; MENGALI; PASSOS, 2009, p. 36).

Pimenta (2008, p. 22) entende que a formação continuada "não se reduz a treinamento ou capacitação", propondo que ela trata de uma modalidade de formação em que são explicitadas as demandas da prática, as necessidades do professor, extraídas dos "conflitos e dilemas de sua atividade de ensinar" (idem, p. 21).

Nesse sentido, a formação continuada do professor que ensina matemática nos anos iniciais do ensino fundamental poderá considerar diferentes dimensões: o processo de formação e profissionalização, questões identitárias, processos de aprendizagem matemática vivenciados em diferentes momentos, bem como as representações que o professor foi construindo sobre a matemática, seu ensino e sua aprendizagem ao longo de sua trajetória como estudante e como docente. Além disso, a formação continuada precisaria procurar favorecer a disponibilidade de reflexão acerca das experiências e dos saberes que envolvem a prática, bem como a participação crítica dos professores. Na formação continuada, seria necessário, portanto, considerar o professor como sujeito sociocultural, situado em um tempo e um espaço, que conjuga em suas ações experiências pessoais e profissionais. 
Em Belo Horizonte, uma parceria da Faculdade de Educação da Universidade Federal de Minas Gerais (UFMG) com a Secretaria Municipal de Educação proporcionou a proposição e realização, a partir de 2006, de um curso de formação continuada para atender a várias áreas de concentração, estando entre elas a Educação Matemática. Trata-se do Curso de Especialização Lato Sensu em Docência para a Educação Básica (LASEB), cuja estrutura curricular é assim descrita por Gomes, Dalben, Rocha e Alves (GOMES et al., 2009, p. 22-23):

A proposta do curso se estruturou em torno de uma base curricular comum, integrada na ideia de um programa que se ramifica por meio de disciplinas específicas a cada uma das áreas de concentração. O curso se configurou com uma carga horária global de 450 horas, distribuídas em duas disciplinas de 60 horas ou 4 créditos cada uma e outras 11 disciplinas de 30 horas ou dois créditos. As duas disciplinas de 60 horas pertencem ao Núcleo Comum, e as 11 disciplinas de 30 horas são as Disciplinas Especificas das áreas de concentração...

Uma das disciplinas do Núcleo Comum é a Análise Crítica da Prática Pedagógica (ACPP), que visa à "formação e ao acompanhamento mais próximo da prática cotidiana do docente" (GOMES et al., 2009, p. 25). Nela, o professor em formação elabora um plano de ação e o desenvolve na escola ou na sala de aula a fim de que possa

refletir sobre o seu fazer, sobre os processos de avaliação do seu trabalho, sobre os processos de ensino e aprendizagem de seus alunos e também seja capaz de organizar, sistematizar atividades e elaborar planejamentos de aula e projetos de ação docente (GOMES et al., 2009, p. 26).

A ACPP inclui a elaboração e execução de um plano de ação na escola ou em sala de aula como trabalho de conclusão da especialização, com a finalidade de possibilitar a transformação das diferentes dimensões de formação docente propostas pelo curso "em processos concretos de reflexão/ação e produção de conhecimento sobre o ensino, a escola e a prática pedagógica vivenciada pelos professores em suas salas de aula e escolas" (GOMES et al., 2009, p. 26).

Como se pode perceber, a proposta do LASEB procurou levar em conta as necessidades indicadas por estudos atualizados sobre a formação continuada tais como os referidos anteriormente (PIMENTA, 2008; NACARATO; MENGALI; PASSOS, 2009), conferindo um papel relevante à articulação entre os aspectos teóricos e práticos da formação e buscando favorecer as reflexões dos docentes acerca de seus saberes e práticas.
A Rede Municipal de Educação de Belo Horizonte, cujos professores têm sido os alunos do LASEB, organiza o trabalho que realiza no Ensino Fundamental numa proposta de ciclos de formação na qual o primeiro ciclo atende as crianças na faixa etária de 6 a 8/9 anos, o segundo ciclo se destina aos alunos com idade entre 9 e 11/12 anos, e o terceiro ciclo agrupa as turmas de estudantes de 12 a 14/15 anos.

Neste artigo, abordamos alguns resultados de uma pesquisa de doutorado desenvolvida pela primeira autora, sob a orientação da segunda, norteada pela seguinte questão: Como os professores que ensinam Matemática no $2^{\circ}$ ciclo de formação da Rede Municipal de Educação de Belo Horizonte que cursaram a especialização em Educação Matemática do Curso de Pós-Graduação Lato Sensu em Docência na Educação Básica - LASEB percebem e narram as contribuições do curso? A partir da questão proposta, as contribuições do Curso de Especialização em Educação Matemática do LASEB foram investigadas em narrativas de professoras que ensinam Matemática no $2^{\circ}$ ciclo de formação da Rede Municipal de Ensino de Belo Horizonte. As narrativas de dez professoras, recolhidas em entrevistas que nos foram concedidas, evidenciaram, em vários aspectos, aproximações e afastamentos das docentes em relação à Matemática, que emergiram como um dos eixos importantes nas análises realizadas em nossa pesquisa e constituem o foco do presente texto.

$\mathrm{Na}$ seção a seguir, procuramos elucidar o leitor a respeito da proposta do Curso de Formação Continuada oferecido no LASEB, conferindo realce à área de Educação Matemática. Depois disso, tecemos algumas considerações de natureza teórico-metodológica acerca da investigação empreendida, discorrendo especialmente sobre a produção das narrativas na perspectiva da história oral e descrevendo os procedimentos utilizados. Por fim, concentramo-nos em análises relativas às aproximações e afastamentos das professoras em relação à Matemática.

\section{O CURSO DE Pós-GraduAÇÃo LATO SENSU ESPECIALIZAÇÃO EM DOCÊNCIA NA EDUCAÇÃo BÁSICA - LASEB - ÁREA DE CONCENTRAÇÃO - EdUCAÇÃo MATEMÁTICA}

O Programa de Especialização Lato Sensu Docência para a Educação Básica - LASEB surgiu de uma demanda apresentada à Faculdade de Educação (UFMG) pela Secretaria Municipal de Educação de Belo Horizonte. Segundo Dalben e Gomes (2009), constituiu-se como uma proposta interinstitucional e multidisciplinar voltada para a formação de "profissionais para o Sistema Municipal de Educação de Belo Horizonte, visando melhorar e aprofundar as bases de desempenho dos docentes 
em relação às áreas e temáticas específicas selecionadas como campos de especialização" (p. 14). O curso teve sua primeira turma em 2006. Em 2009, envolveu cinco áreas de concentração - Alfabetização e Letramento; Educação Infantil; Educação Matemática; História da África e Cultura Afro-Brasileira e Juventude e Escola. ${ }^{1}$

A concepção de formação continuada proposta pelo LASEB admite que

Um projeto de formação continuada é, em si, um espaço de interação entre dimensões pessoais e profissionais; aos professores é facultado apropriarem-se dos processos de formação para, pessoalmente, dar-lhes um sentido no quadro de suas histórias de vida e de suas histórias profissionais (GOMES, et al., 2009, p. 22).

A concepção preliminar do curso, conforme Dalben (2009), "se direcionou à organização de espaços em que o próprio professor e sua prática pudessem se situar no centro dos trabalhos" (p. 318). Nesse sentido, como eixo da proposta do LASEB, a disciplina ACPP - Análise Crítica da Prática Pedagógica teve como objetivo principal

atribuir mais sentido às teorias estudadas e enriquecer as reflexões e elaborações sobre práticas pedagógicas desenvolvidas pelo/as docentes, a fim de favorecer o diagnóstico e a análise de seu trabalho e estimular iniciativas para transformações requeridas pelas demandas cotidianas da escola (ZAIDAN; SOUTO, 2009, p. 211).

A investigação é concebida como uma atitude importante na formação do professor. Desse modo, o eixo da pesquisa como fator educativo constitui, no curso, a mediação metodológica da proposta curricular na perspectiva de "criar o perfil de um docente inquieto e inquiridor diante da prática, que não se contenta com o usual, que busca oferecer o melhor - e para isso estuda, investiga, cria e ensina" (DALBEN, 2009, p. 321).

Para a turma que acompanhamos nos anos de 2009 a 2010, o curso foi oferecido aos sábados, com a duração de 18 meses. Partindo de objetivos básicos a serem atingidos, da demanda da SMED e das diretrizes da FAE-UFMG, a proposta do curso pautou-se, segundo Gomes, Dalben, Rocha e Alves (GOMES et al., 2009), nos seguintes princípios norteadores: 1) a valorização da experiência profissional dos professores; 2) a reflexão sobre essa experiência para a tomada de consciência e distanciamento crítico necessários para que se constitua objeto de reflexão; 3) a ênfase na pluralidade e no respeito à identidade cultural dos sujeitos (professores e alunos) destinatários dessa formação; 4) o uso de diferentes tecnologias de informação com a finalidade de ampliação dos horizontes teórico-metodológicos de produção de conhecimentos; 5) reflexão e análises relativas aos problemas educacionais, tendo em vista a realidade atual da educação no município, estado, país e mundo; 6) reflexão sobre questões da atualidade relativas à produção do conhecimento e às fronteiras entre as disciplinas; 7) ênfase na construção e reconstrução da identidade profissional do professor diante do contexto contemporâneo.

Para o desenvolvimento do projeto do LASEB na área de Educação Matemática, Zaidan (2009) discute quatro questões como referências fundamentais. A primeira delas é a importância de se propiciar um estudo de Matemática aos alunos da Educação Básica. Para a autora, essa questão baseia-se no pressuposto do "reconhecimento da relevância social dos conhecimentos matemáticos na formação da infância à vida adulta, não havendo escola ou nível de educação que prescinda de seu ensino" (p. 53). A segunda questão refere-se à contextualização da área, na compreensão sobre o ensino, sobre os processos de aprendizagem, sobre os conteúdos, nas condições atuais da realidade brasileira. A terceira questão relaciona-se à necessidade de atualização do objeto de ensino do campo da Educação Matemática. Finalmente, a quarta questão concerne à compreensão sobre as condições de trabalho da docência, que se alteraram nas últimas décadas.

Segundo a autora,

A proposta da área busca proporcionar ampliação da formação teórica específica em Matemática, ao lado da discussão de metodologias de ensino nas condições da prática escolar. Situa ainda a iniciativa de contato com a diversidade de produção existente, com a discussão de desafios e dificuldades da aprendizagem em Matemática, com o ensino por projetos e o uso de tecnologias. Tudo isso se articula à análise da prática pedagógica e a uma valorização da vivência e da convivência nos processos formativos (ZAIDAN, 2009, p. 59).

A estrutura curricular do curso conta com uma carga horária de 450 horas, que assim se distribui:

- duas disciplinas de 60 horas que pertencem a um núcleo comum² do Programa: Seminários de Pesquisa e Docência na Educação Básica; Análise Crítica da Prática Pedagógica - ACPP;

- onze disciplinas específicas de cada área de concentração, cada uma delas com 24 horas.

Das disciplinas específicas do LASEB, três são comuns a todas as áreas de concentração, por constituírem temáticas referentes à formação geral do professor. São elas: Currículo, Teoria e Prática; Sociedade, Cultura e Educação; Pesquisa e Intervenção na Escola. 
As disciplinas específicas exclusivas da Educação Matemática são: A Educação Matemática; Fundamentos do Ensino de Matemática I - Números de contagem: surgimento, organização e significados; Fundamentos do Ensino de Matemática II - Números de medidas: surgimento, organização e significados; Fundamentos do Ensino de Matemática III - Iniciação à Álgebra; Fundamentos do Ensino de Matemática IV - Geometria plana e espacial; Fundamentos do Ensino de Matemática $\mathrm{V}$ - Tratamento da informação estatística e probabilidade; O ensino de Matemática e os projetos interdisciplinares; As tecnologias e o ensino de Matemática.

A proposta do LASEB baseia-se em trazer o professor e sua prática para a centralidade do processo. Afirma-se, na proposição do curso, que as atividades possibilitam o diálogo e que se pretende instigar a atividade crítica e investigativa ao se apresentar a pesquisa como perspectiva para o trabalho.

\section{ASPECTOS TEÓRICO-METODOLÓGICOS}

Para nós, em concordância com Garnica, Fernandes e Silva (2011, p. 232), embora metodologia não se reduza a um conjunto de ações, cabe "optar por um conjunto de ações (procedimentos) que nos permita abordar/ compreender algo". Entretanto, trata-se, também, "de saber quais as potencialidades e os limites dessas ações, quais seus fundamentos, qual o terreno em que tais ações se assentam".

Compreendendo que o estudo do método está relacionado com o conjunto dos caminhos percorridos pelas ciências para a produção dos seus conhecimentos, esses trajetos encontram-se articulados a uma abordagem epistemológica. $\mathrm{O}$ ato de pesquisar é processo histórico e, em decorrência desse caráter, encontramos diferentes concepções de ciência e de método, cada uma pressupondo formas diferenciadas de investigação. Em nosso estudo, fundamentamo-nos teórica e metodologicamente na teoria crítica, por considerarmos a compatibilidade entre os princípios epistemológicos e metodológicos desse paradigma e o objeto de pesquisa.

Kincheloe e McLaren (2006, p. 286) observam que, para os pesquisadores críticos, a linguagem não é um espelho da sociedade, tampouco um conduto neutro e objetivo de descrição do mundo real. "Em vez disso, a partir de uma perspectiva crítica, as descrições linguísticas não servem simplesmente para explicar o mundo, mas para construí-lo".

Uma posição decorrente da teoria crítica nas questões relacionadas à objetividade e à subjetividade é vista em Mazzotti e Gewandsznajder (2000, p. 140), quando os autores ressaltam que, para os adeptos da teoria crítica
A objetividade nada tem a ver com as leis "naturais" ou com a "natureza" a ser descoberta, assim como a subjetividade não é algo que tenha que ser expurgado da pesquisa, e sim algo que precisa ser admitido e compreendido como parte da construção de significados inerentes às relações sociais que se estabelecem no campo pesquisado.

Vista sob essa perspectiva, a subjetividade ganha ênfase por assumir importante papel no processo de pesquisa, tanto no que se refere aos pesquisados quanto às possibilidades dadas à observação e à análise de dados pelo pesquisador.

Nesse sentido, parte-se do pressuposto de que a subjetividade está presente na circulação de saberes docentes, nos discursos produzidos pelos professores e, sendo assim, os métodos e procedimentos de pesquisa devem considerá-la. "A subjetividade é uma condição necessária do conhecimento social" (GARNICA, 2007, p. 35).

Nossa investigação utilizou como recurso metodológico a história oral, ${ }^{3}$ concebida como um método de pesquisa qualitativo que possibilita a vinculação entre a memória/oralidade e outras fontes documentais.

Com a intenção de estudar as contribuições do Programa de Especialização Lato Sensu em Docência na Educação Básica - LASEB, a partir de narrativas de professores que ensinam Matemática, recorremos a um método que pudesse conduzir ao tipo de relação que pretendíamos estabelecer com o objeto. Foi nesse contexto que trabalhamos com a história oral, método que, segundo Garnica (2007, p. 20), busca

\begin{abstract}
abordar o acontecimento social sem classificações prévias, optando por abrir os vários planos discursivos de memórias várias, considerando as tensões entre as histórias particulares e a cultura que as contextualiza. O sujeito, que se constitui a si próprio no exercício de narrar-se, explica-se e dá indícios, em sua trama interpretativa, para compreensão do contexto no qual ele está se constituindo (GARNICA, 2007, p. 20).
\end{abstract}

Usar história oral não significa conferir um tratamento histórico ao tema pesquisado. Ao trabalhar com história oral, no entanto, aproximamo-nos de questões historiográficas e criamos fontes historiográficas. "O que ocorre em história oral é que a opção por seguir esse método implica intencionalmente constituir fontes historiográficas - sejam essas fontes usadas ou não, no presente ou no futuro, como tal" (GARNICA; FERNANDES; SILVA, 2011, p. 237; grifos no original).

As narrativas são fontes a partir das quais outras fontes podem ser constituídas. As professoras que ensinam Matemática no $2^{\mathrm{O}}$ ciclo de formação da Rede Municipal de Educação de Belo Horizonte construíram narrativas em situações de entrevista, constituindo-se, 
ao relatarem suas memórias do curso, em depoentes participantes da pesquisa que geraram fontes legítimas para a investigação.

Mediante as fontes orais, é possível perceber não somente as declarações sobre o que as professoras fizeram durante o processo de formação continuada proporcionada pelo curso do LASEB, mas também sobre o que queriam fazer, sobre o que acreditavam estar fazendo e sobre o que, naquele momento da entrevista, pensavam que faziam durante o curso e como consequência dele.

As histórias contadas permitem uma aproximação entre as experiências narradas e a prática produzida, ou seja, uma aproximação entre a prática já realizada e a narrativa sobre essa prática. Nessa perspectiva, usar a oralidade, ao mesmo tempo que viabiliza a transmissão das memórias do curso, concede ao entrevistado um momento de parada para refletir sobre o vivido com o olhar atual, um momento de ressignificação de saberes. Nesse sentido, essa modalidade de coleta das fontes orais em nossa pesquisa foi também um momento de reflexão.

Para dar início à nossa investigação, no período de setembro de 2009 a dezembro de 2010, acompanhamos alguns momentos do processo de formação da quarta turma do Programa de Especialização Lato Sensu Docência para a Educação Básica - LASEB na área de concentração "Educação Matemática" no curso desenvolvido de agosto de 2009 a dezembro de 2010.

As observações começaram em setembro de 2009, quando tivemos o primeiro contato com o grupo de professores matriculados na turma, composta por 29 docentes atuantes no $1^{\circ}, 2^{\circ}$ e $3^{\circ}$ ciclo de formação em escolas da Rede Municipal de Educação de Belo Horizonte (RME-BH). Nessa ocasião, a primeira autora apresentou-se ao grupo de professores e lhes falou sobre as intenções de pesquisa, procurando esclarecer os objetivos da investigação e conversar sobre a possibilidade de participar de alguns momentos do processo de formação. Tendo acordado com os docentes essa última proposta, durante o segundo semestre de 2009 a primeira autora esteve presente em uma das três aulas de cada disciplina proposta para o semestre. ${ }^{4}$

A turma contava com 29 professores, sendo 22 do sexo feminino e sete do sexo masculino. Desses docentes, 93\% ensinavam Matemática, mas trabalhavam também com outras disciplinas, e $14 \%$ ensinavam apenas Matemática. Onze professoras lecionavam no $2^{\circ}$ ciclo de formação da RME-BH. Nosso interesse em desenvolver o estudo com professores do 2 o ciclo vinculava-se a uma lacuna que havíamos percebido nesse ciclo de formação. Em decorrência da ênfase do $1^{\circ}$ ciclo na alfabetização, os estudantes chegam ao $2^{\mathrm{o}}$ ciclo apresentando muitas dificuldades relativas ao conhecimento matemático, e a situação é agravada pelas dificuldades dos professores em relação ao conhecimento matemático. No $2^{\circ}$ ciclo, são necessárias sistematizações desses conhecimentos com as quais o estudante não teve oportunidade de trabalhar anteriormente, e os docentes encontram muita dificuldade em enfrentar essa situação devido às limitações de seus próprios conhecimentos matemáticos. Assim, experiências anteriores nos indicavam a necessidade de aproximação das práticas docentes desenvolvidas no $2^{\mathrm{Q}}$ ciclo de formação.

Das onze professoras da quarta turma do LASEB que lecionavam para o $2^{\mathrm{O}}$ ciclo, dez aceitaram colaborar conosco e participaram efetivamente de nossa pesquisa. ${ }^{5}$ O Quadro 1 (abaixo) apresenta nossas colaboradoras, sua formação acadêmica de graduação, sua idade e tempo de trabalho na RME-BH na ocasião das entrevistas que realizamos. ${ }^{6}$

\section{Quadro 1}

\begin{tabular}{|l|c|l|c|}
\hline \multicolumn{1}{|c|}{ Professora } & Idade & \multicolumn{1}{c|}{ Formação } & $\begin{array}{c}\text { Tempo de } \\
\text { trabalho na } \\
\text { RME-BH } \\
\text { (anos) }\end{array}$ \\
\hline Ângela & 49 & Administração de Empresas & 25 \\
\hline Eliane & 50 & Normal Superior & 25 \\
\hline Érica & 44 & Pedagogia & 9 \\
\hline Maria Aparecida & 49 & Pedagogia & 26 \\
\hline Cristina & 35 & $\begin{array}{l}\text { Psicologia e Licenciatura } \\
\text { em Ciências }\end{array}$ & 7 \\
\hline Maria Inês & 45 & Administração e Pedagogia & 8 \\
\hline Simone & 44 & Pedagogia & 20 \\
\hline Sônia & 44 & Pedagogia & 7 \\
\hline Vanessa & 47 & Pedagogia & 20 \\
\hline Vanilda & 41 & Pedagogia & 8 \\
\hline
\end{tabular}

Anteriormente à entrevista, todas as professoras participantes foram esclarecidas sobre os objetivos da pesquisa, bem como sobre os procedimentos utilizados. Ainda que algumas colaboradoras tenham optado por conhecer o roteiro somente no momento da entrevista, o acesso prévio a esse roteiro foi oferecido a todas elas. Para o registro do momento da entrevista, escolhemos como suporte a videogravação, para termos acesso, posteriormente, não somente às vozes coletadas, mas também às imagens das expressões das professoras. Compartilhamos a consideração de Garnica (2007, p. 53):

Não há um registro definitivo de fatos pois não há fatos; há sempre uma percepção, um modo de comunicar as intenções, um "algo" que se mostra em perspectiva, uma perspectiva (a do falante) que mais frequentemente é compreendida segundo outra perspectiva (a do ouvinte), e as perspectivas, quaisquer que sejam elas, portanto, escapam às tentativas de apreensão quer pela malha da imagem, quer pela do som ou da escrita. 
Após a gravação das entrevistas, foi realizada sua transcrição, tendo o registro da oralidade coletado em suporte digital sido convertido em um primeiro registro escrito. Como Garnica, Fernandes e Silva (2011, p. 235), consideramos que registros diferentes não são manifestações distintas de uma mesma coisa, e sim coisas distintas, sujeitas a instrumentos distintos de análise. Se a oralidade é o ponto de partida para nossa compreensão, a escrita é nosso ponto de partida para a análise formal.

Como é comum acontecer, as transcrições de nossas entrevistas apresentavam as características da linguagem oral, com repetições de palavras, interrupções de frases, uso de gírias e expressões populares, marcadores conversacionais. Também eram evidentes as lacunas geradas pelo uso natural, da parte de nossas colaboradoras, de recursos não verbais de linguagem, como expressões fisionômicas, diferentes entonações, ritmos e gestos.

Ao transcrever oralidades, percebemos que o texto transcrito fica difícil de ler, pois a dinâmica da fala é diferente dos modos de construção da escrita. Com o cuidado de procurar não comprometer os sentidos deixados pelas entrevistadas, realizamos o processo de textualização, isto é, empreendemos uma editoração da transcrição, na qual optamos por uma reordenação temática das falas transcritas e pela organização das narrativas de nossas colaboradoras na forma de um conjunto de excertos. ${ }^{7}$

As professoras participantes assinaram documentos autorizando a utilização dessas narrativas na pesquisa e cedendo a nós os direitos sobre as gravações, as transcrições e as textualizações das entrevistas. As textualizações, como tem ocorrido nos trabalhos do GHOEM - Grupo de Pesquisa História Oral e Educação Matemática, ${ }^{8}$ constituíram o suporte principal para nossas análises.

\section{ANÁLISE DAS NARRATIVAS DAS PROFESSORAS: APROXIMAÇÕES E AFASTAMENTOS EM RELAÇÃO À MATEMÁTICA}

As narrativas não recompõem os fatos literalmente. São reconstruções daquilo que na memória ficou dos fatos vividos. Assim, elas constituem uma representação do que foi vivenciado por cada pessoa entrevistada que, nesse trabalho de reconstrução dos fatos, poderá modificá-los por influência do distanciamento entre o fato vivido e as memórias relatadas. No caso de nossa pesquisa, reflexões sobre as práticas docentes que desenvolvem mais recentemente são também elementos que repercutem nas representações das professoras acerca do curso que realizaram. Nessa perspectiva, ao relatar suas memórias do curso, as professoras falaram do que aprenderam, do que consideram ter sido modificado em suas práticas desde aqueles momentos.

A atividade de narrar memórias do curso e de suas práticas desencadeou-se a partir de um processo em que as professoras precisaram tomar consciência de seus próprios saberes para transmiti-los, o que Tardif (2008) denomina objetivação parcial dos saberes.

Nossas colaboradoras narraram suas experiências no LASEB, avaliaram o curso e a si próprias. A imersão nas textualizações levou-nos a perceber alguns temas recorrentes nas narrativas das professoras participantes, $\mathrm{o}$ que já esperávamos, tendo em vista o roteiro que orientou nossas entrevistas. Um desses temas constituiu o eixo de análise das aproximações e afastamentos das docentes em relação à Matemática, que aqui focalizamos.

Nas narrativas, localizamos um número considerável de registros de fracassos, sucessos, ansiedades e temores em relação à Matemática, bem como muitas referências às práticas para ensinar Matemática desenvolvidas pelas professoras. Um elemento importante a ser realçado reside na motivação das colaboradoras para cursar a Especialização em Educação Matemática no LASEB. Além do peso atribuído por elas à instituição formadora, a especificidade da área escolhida foi destacada nos relatos. Nenhuma das dez professoras teve sua formação acadêmica de graduação em Matemática. A opção pela especialização em Educação Matemática se deu, em alguns casos, por afinidade, em outros por necessidade. Percebemos que ambos os tipos de demandas foram desencadeados nas trajetórias profissionais de nossas entrevistadas.

Os depoimentos das professoras Ângela, Cristina, Maria Aparecida, Simone e Vanessa nos permitiram compreender que a aproximação em relação ao ensino da Matemática foi se consolidando ao longo de seus percursos docentes, e as professoras procuraram na especialização em Educação Matemática o aprimoramento de suas práticas de ensino de Matemática. Ângela declarou gostar de Matemática e disse que queria fazer uma especialização bem feita. Procurou a Educação Matemática por acreditar que o curso iria forçá-la a estudar. Cristina já trabalhava com o ensino da Matemática e o fato de gostar de Matemática levou-a a buscar uma complementação para a disciplina que lecionava. Maria Aparecida gosta de ensinar Matemática e buscou no LASEB subsídios para continuar no que já trabalhava. Simone afirmou que há dez anos vem escolhendo lecionar Matemática. Procurou pela especialização em Educação Matemática para aprimorar o que fazia. Vanessa gosta de Matemática e escolheu a especialização em Educação Matemática para aprimorar aquilo que estava dando para as crianças na sala de aula.

Nos depoimentos das outras professoras, percebemos que a busca pela especialização em Educação Matemática 
ocorreu por necessidades advindas de suas práticas pedagógicas, em alguns casos por considerarem a precariedade do próprio conhecimento e em outros por ainda não terem efetivamente assumido a docência da disciplina. Nas duas situações, a busca pelo curso decorreu de uma suposta carência de cada uma delas em relação ao conhecimento matemático ou a alternativas didáticopedagógicas para trabalhá-lo. Eliane não mencionou dificuldades e gosta de Matemática. Queria aprender coisas novas para não deixar a aula muito cansativa. Queria dar uma aula melhor, mais agradável para ela e para os alunos também. Érica não lecionava Matemática, mas sabia que poderia vir a trabalhar com a disciplina. Procurou a especialização em Educação Matemática pela necessidade de aprimoramento, de crescimento profissional de conhecimentos na área de Matemática. Maria Inês, embora não tenha explicitado dificuldades em relação ao conhecimento matemático, achou que o curso tinha tudo a ver com o que estava precisando para seu trabalho de coordenadora, pois poderia levar o conhecimento aprendido para os professores da sua escola, que ensinam Matemática no $2^{\mathrm{O}}$ ciclo. Sônia não lecionava Matemática. Queria fazer a especialização em alfabetização, mas fez a opção por Educação Matemática pelo fato de sua dificuldade ser maior nessa área. $\mathrm{O}$ curso foi um desafio para a professora, que disse nunca ter sido boa em Matemática. Vanilda disse que escolheu a Especialização em Educação Matemática porque, nos últimos três anos, vem trabalhando com Matemática na escola, e tem dificuldade com alguns temas.

A maioria das professoras procurou o LASEB para aprender Matemática. Essa busca foi mobilizada pelas dificuldades enfrentadas em suas práticas docentes no que se refere aos conhecimentos de Matemática. Percebemos que muitas delas, apesar de lecionarem Matemática, se sentem inseguras. Afastam-se da Matemática mobilizadas por medos e ansiedades, aproximaram-se do LASEB para aprender Matemática.

Nossa pesquisa mostrou, porém, que várias professoras não tiveram suas expectativas de aprender Matemática atendidas no LASEB. Suas narrativas nos levaram a perceber que esperavam aprender conteúdos que contribuiriam para a solução de suas dificuldades. Vanilda queria ter se aprofundado mais nos conteúdos da Matemática para trabalhar com os alunos e pensa que faltou tempo para isso. Maria Inês considerou que o tempo foi insuficiente para tratar as especificidades do conhecimento matemático necessário para o professor que atua nos anos iniciais do Ensino Fundamental. A professora Cristina tinha expectativas em relação à geometria e revelou sua frustração ao dizer que esse aspecto deixou a desejar. Sônia considera que, do curso, alguma coisa ficou. Nossa leitura é de que a grande rapidez do curso não possibilitou a consolidação dos conhecimentos dessas docentes. A ideia do pouco tempo atribuído às disciplinas que compunham o curso do LASEB justifica, recorrentemente nos relatos, a lacuna de conhecimentos matemáticos sentida pelas professoras.

A aprendizagem do conteúdo de que necessitam para o desenvolvimento de suas práticas docentes envolve uma posse de conhecimentos que as professoras considerem suficiente para que sejam capazes de elaborar metodologias para a aprendizagem de seus estudantes. Para que isso ocorra, há que se considerar a aprendizagem das professoras. Nacarato, Mengali e Passos (2009) nos ajudam a compreender essa dimensão da aprendizagem ao ponderarem sobre seu caráter gradativo:

Temos a convicção de que aprender seja um processo gradual, que exige estabelecimento de relações. A cada situação vivenciada, novas relações vão sendo estabelecidas, novos significados vão sendo produzidos e esse movimento possibilita avanços qualitativos no pensamento matemático (p. 34).

As professoras participantes, docentes da Rede Municipal de Belo Horizonte, foram aprovadas em um concurso para lecionar qualquer disciplina até o $6^{\mathrm{O}}$ ano do Ensino Fundamental. A Matemática não foi a disciplina preferida pela maioria das nossas colaboradoras, que se aproximaram dela em consequência da demanda imposta pelo cargo assumido na RME-BH. Nosso grupo de entrevistadas é constituído por professoras que atuam no $2^{\circ}$ ciclo da RME, ou seja, no $4^{\circ}, 5^{\circ}$ e $6^{\circ}$ anos do Ensino Fundamental. Como elas próprias comentam, seus alunos tiveram precária formação matemática, pois a ênfase do processo formativo do $1^{\circ}$ ciclo reside na alfabetização. As narrativas revelam o descontentamento das professoras frente às dificuldades apresentadas por seus alunos. E essas dificuldades também são vivenciadas por elas no que se refere ao próprio conhecimento.

Tradicionalmente a Matemática vem sendo tratada como uma disciplina difícil e, portanto, não acessível para todos; atribui-se a ela grande responsabilidade na exclusão de muitos alunos.

A Matemática é geralmente tida como uma disciplina extremamente difícil, que lida com objectos e teorias fortemente abstractas, mais ou menos incompreensíveis. Para alguns salienta-se o seu aspecto mecânico, inevitavelmente associado ao cálculo. É uma ciência usualmente vista como atraindo pessoas com o seu quê de especial. Em todos estes aspectos poderá existir uma parte de verdade, mas o facto é que em conjunto eles representam uma grosseira simplificação, cujos efeitos se projectam de forma intensa (e muito negativa) no processo de ensino-aprendizagem (PONTE, 1992, p. 1). 
O fracasso na aprendizagem da Matemática foi por muito tempo justificado com base em uma suposta pouca capacidade de aprendizagem do aluno. Essa perspectiva é predominante no discurso de muitos professores e apareceu nas narrativas das professoras participantes. Vanilda nos disse que foi fazer o curso para tentar ajudar mais os alunos a entender, queria descobrir como fazer para que os alunos envolvessem e se interessassem mais pela Matemática. Maria Inês está convencida de que $a$ criança tem que perder o medo e aprender a lidar com a Matemática. Cristina relaciona sua prática com alunos de inclusão ${ }^{9}$ com a dificuldade dos alunos em aprender Matemática.

Essa ideia da Matemática como uma disciplina difícil, também partilhada pelas professoras, integra as concepções que elas foram construindo sobre a Matemática, seu ensino e, consequentemente, a concepção de formação docente que subsidiou a busca, no LASEB, por alternativas de trabalho que pudessem fazer frente às dificuldades enfrentadas com o ensino de Matemática. Vanilda acha que um curso para formar professores tem que ter prática. Tem que contemplar o que tem aparecido nas avaliações sistêmicas. É necessário trazer para a gente o que tem aí no mercado. Para Maria Inês, o curso deve apresentar a teoria de forma resumida e propor atividades para que o professor possa aplicar. Érica considera que um curso para formar professores deve ser voltado para a didática, mostrando como é. Eliane acha que um curso de formação docente tem que ouvir o professor para conhecer suas dificuldades e, então, propor atividades de que ele esteja necessitando.

Essas demandas de formação presentes nas narrativas das professoras remetem ao modelo de formação amparado pela racionalidade técnica (SHÖN, 2000; FIORENTINI; SOUZA JR.; MELO, 2007; DINIZPEREIRA, 2008), um tipo de formação que concebe a prática como lócus de aplicação de conhecimentos teóricos previamente organizados pela ciência, que não consegue atingir a pluralidade do processo, as múltiplas dimensões que envolvem o aprender e o não aprender. Provavelmente, esse foi o tipo de formação inicial de nosso grupo de colaboradoras. Buscamos, então, a seguir, discutir a formação acadêmica das professoras, focalizando especificamente algumas questões ligadas aos conhecimentos matemáticos.

Como dissemos anteriormente, nenhuma das professoras graduou-se em Matemática. Érica, Maria Aparecida, Maria Inês, Simone, Sônia, Vanessa e Vanilda formaram-se em Pedagogia. Eliane formou-se no Curso Normal Superior, Ângela em Administração de Empresas e Cristina em Psicologia, com Licenciatura em Ciências.

Assim, o grupo que estudamos é constituído, em sua maioria, por professoras que têm formação acadêmica inicial denominada usualmente como de generalistas ou polivalentes, com pouca ênfase para o conhecimento matemático e seu ensino. Observamos, ainda, que a maior parte das professoras que cursou Pedagogia concluiu o curso antes de 2004. Vale considerar a análise realizada por Curi (2008) a respeito das grades curriculares e ementas que envolvem a Matemática nos cursos de Pedagogia do país, em vigor na ocasião de sua pesquisa, ${ }^{10}$ concluída em 2004, cujos dados evidenciam a fragilidade da formação inicial relativa à Matemática oferecida aos professores que atuam nos anos iniciais do Ensino Fundamental. Como foi mencionado anteriormente, estudos sobre a formação de professores que ensinam Matemática nos anos iniciais do Ensino Fundamental vêm evidenciando problemas como a centralidade da formação em processos metodológicos, com pouca ênfase nos conhecimentos matemáticos e a predominância de grades curriculares caracterizadas pela falta de disciplinas voltadas para a formação matemática.

A precariedade do conhecimento matemático veiculado na formação inicial parece contribuir com as representações ${ }^{11}$ que as professoras vão construindo acerca do lugar docente em relação à Matemática. Nossas colaboradoras trouxeram a imagem de que ocupavam um lugar de menor conhecimento em relação aos colegas de turma no LASEB. Mostraram reconhecer, nos professores do $3^{\circ}$ ciclo, autoridade quanto ao saber matemático. No entanto, no que se refere aos aspectos metodológicos, achavam-se em melhores condições para expor suas experiências, como atestam vários depoimentos recolhidos nas entrevistas individuais que realizamos. O teor desses depoimentos tem participação importante na caracterização dos afastamentos e aproximações das professoras em relação à Matemática. Encontramos exemplos das representações do lugar docente quanto à Matemática nas narrativas de Érica e Maria Inês.

Assim, enquanto Érica nos disse que, como pedagoga, está muito aquém dos professores que fizeram Matemática, considerando que pensava menos e que eles sabiam mais. Érica constata que eles sabem mais, pois detêm o conhecimento matemático, mas acha que isso não significa que eles saibam ensinar. Para Érica, saber ensinar é mais importante ou tão importante quanto o conhecimento de Matemática.

A narrativa de Maria Inês evidenciou que, para ela, os professores de 3 o ciclo, formados em Matemática, precisam de didática, de metodologia, carecem perceber quem são os alunos com quem trabalham e conhecer quais são suas demandas. Em contrapartida, ela pensa que o professor que ensina Matemática nos $1^{\circ}$ e $2^{\circ}$ ciclos identifica o aluno e suas demandas, mas tem dificuldade de atuar por falta de conhecimento matemático e de saber ensinar Matemática. 
Contudo, simultaneamente à presença de relatos que testemunham em favor da permanência das inseguranças quanto ao próprio conhecimento matemático, as narrativas também mostram alguns balanços positivos das colaboradoras após o LASEB. Um destaque está nas falas de Simone, Maria Aparecida e Cristina sobre as temáticas que desenvolveram no plano de ação elaborado na disciplina Análise Crítica da Prática Pedagógica e executado como trabalho de conclusão do curso.

Simone disse que o que achou mais interessante e aquilo em que passou mais tempo pensando foi sobre a questão da divisão. Concluiu sobre as dificuldades desse conteúdo: E eu acabei vendo que é isso, essa dificuldade que a gente percebe, ela existe, ela é fato, até pela operação em si. Maria Aparecida declarou ter se sentido muito envolvida e interessada em trabalhar com o seu plano de ação, relacionado ao sistema de numeração, no qual procurou alguma coisa que pudesse estimular seu interesse e aumentar a sua capacidade. Cristina remeteuse ao tratamento da informação, tema que considerou muito interessante, sobre o qual desenvolveu o seu plano de ação e no qual considerou mais se ter aprofundado.

\section{Alguns APONTAMentos PARA CONCLUIR}

As narrativas que analisamos nos permitiram compreender que o curso do LASEB marcou positivamente a história de formação docente das dez professoras que participaram de nossa investigação, pela oportunidade de estudar e concluir uma pós-graduação na Universidade Federal de Minas Gerais, pela oportunidade de interações com professores reconhecidos academicamente, pelas aprendizagens e trocas de experiências ocorridas. Todavia, houve também insatisfações e frustrações de expectativas entre as docentes. $\mathrm{O}$ ponto de maior incidência dessas manifestações localizou-se na fragilidade dessas professoras em relação ao próprio conhecimento matemático. Até nas narrativas daquelas professoras que declararam gostar de Matemática e ter experiência com o ensino da disciplina, percebemos descontentamento quanto ao que esperavam aprender sobre os conteúdos matemáticos. As narrativas trazem marcas reveladoras de que o curso deixou a desejar naquilo que se refere ao conhecimento de Matemática, e de que os resultados foram frágeis para a sustentação do papel de professoras que ensinam Matemática nos anos iniciais do Ensino Fundamental. Concordamos com Zaidan quando a autora, ao expressar suas percepções a respeito das experiências com as turmas do LASEB, destaca que "nas condições das práticas atuais, são essenciais o contato, o estudo e a prática do(a) professor(a) dos anos iniciais com o conhecimento matemático escolar" (ZAIDAN, 2009, p. 66).
As insatisfações das professoras são dirigidas especialmente ao conhecimento acerca do ensino de Matemática. Queriam aprender sobre o ofício que desempenham, aprender Matemática para aprender a ensinar. A ideia de que o tempo foi o grande vilão, explícita nas falas das professoras, nos convoca a concordar que a aprendizagem demanda o relacionamento de concepções, práticas e conflitos que envolvem o exercício de reflexão, a incorporação de conhecimentos, experimentos e constatações. Nesse sentido, reportamo-nos a Nacarato, Mengali e Passos (2009) quando enfatizam sua convicção de que aprender é "um processo gradual, que exige estabelecimento de relações" (p. 34). Junto com as autoras, acreditamos que "a cada situação vivenciada, novas relações vão sendo estabelecidas, novos significados vão sendo produzidos e esse movimento possibilita avanços qualitativos no pensamento matemático" (idem).

Por outro lado, as narrativas nos levaram a entender que as colaboradoras da pesquisa exprimem representações sobre os saberes docentes dos professores que ensinam Matemática. Em nossa interpretação, os professores que ensinam Matemática nos anos iniciais, que não cursaram graduação em Matemática, estão conscientes de que possuem saberes práticos, ou seja, "saberes específicos que são baseados em seu trabalho cotidiano e no conhecimento de seu meio" (TARDIF, 2008, p. 38).

As professoras que ensinam Matemática nos anos iniciais do Ensino Fundamental e que participaram da quarta turma do LASEB, com suas representações sobre a Matemática e seu ensino construídas em suas histórias de aprendizagem e formação profissional, embora considerem que não aprenderam a Matemática necessária para ensinar, são conscientes de que aprenderam a olhar, ouvir e compreender o estudante para assim exercerem a docência.

\section{REFERÊNCIAS}

CURI, E. Análise das propostas presentes no material de Matemática do PEC-Universitário, à luz de resultados de investigações e teorias sobre formação de professores. In: NACARATO, A. M.; PAIVA, M. A. V. (Org.). A formação do professor que ensina matemática: perspectivas e pesquisas. Belo Horizonte: Autêntica, 2008. p. 61-76.

DALBEN, A. I. L. F. Formação continuada de professores em nível de especialização: um investimento público que vale à pena? In: DALBEN, A. I. L. F.; GOMES, M. F. C. (Org.). Formação continuada de docentes da Educação Básica: construindo parcerias (LASEB). Belo Horizonte: Autêntica, 2009. p. 315-329.

DALBEN, A. I. L. F; GOMES, M. F. C. (Org.). Formação continuada de docentes da Educação Básica: construindo parcerias (LASEB). Belo Horizonte: Autêntica, 2009. 
DINIZ-PEREIRA, J. E. A pesquisa dos educadores como estratégia para construção de modelos críticos de formação docente. In: DINIZ-PEREIRA, J. E.; ZEICHNER, K. M. (Org.). Pesquisa na formação e no trabalho docente. Belo Horizonte: Autêntica, 2008. p. 11-42.

FIORENTINI, D. et al. Formação de professores que ensinam matemática: um balanço de 25 anos da pesquisa brasileira. Educação em Revista, Belo Horizonte, UFMG, n. 36, p. 137-160, 2002.

FIORENTINI, D.; SOUZA JR., A.; MELO, G. Saberes docentes: um desafio para acadêmicos e práticos. In: GERALDI, C. M. G; FIORENTINI, D.; PEREIRA, E. M. A. (Org.). Cartografias do trabalho docente. Campinas: Mercado das Letras, 2007. p. 307-335.

GARNICA, A. V. M. História oral em educação matemática: outros usos, outros abusos. Guarapuava: SBHMat, 2007. (Coleção História da Matemática para Professores).

GARNICA, A. V. M; FERNANDES, D. N.; SILVA, H. Entre a amnésia e a vontade de nada esquecer: notas sobre regimes de historicidade e história oral. Bolema, Rio Claro, v. 25, n. 41, p. 213-250, dez. 2011.

GOMES, M. F. C. et al. Eixos metodológicos, estrutura curricular e dinâmica de funcionamento de 12 turmas formadas pelo LASEB. In: DALBEN, A. I. L. F.; GOMES, M. F. C. (Org.). Formação continuada de docentes da Educação Básica: construindo parcerias (LASEB). Belo Horizonte: Autêntica, 2009. p. 19-30.

JODELET, D. Representações sociais: um domínio em expansão. In: JODELET, D. (Org.). Representações sociais. Rio de Janeiro: Eduerj, 2001. p. 17-44.

KINCHELOE, J.; MCLAREN, P. Repensando a teoria crítica e a pesquisa qualitativa. In: DENZIN, N.; LINCOLN, Y. O planejamento da pesquisa qualitativa: teorias e abordagens. Porto Alegre: Artmed, 2006.

MAZZOTTI, A. J. A.; GEWANDSZNAJDER, F. O método nas ciências naturais e sociais. 2. ed. São Paulo: Pioneira, 2000.

NACARATO, A. M. A formação matemática das professoras das séries iniciais: a escrita de si como prática de formação. Bolema, Rio Claro, v. 23, n. 37, p. 905-930, 2010.

NACARATO, A. M; MENGALI, B. L. S.; PASSOS, C. L. B. A matemática nos anos iniciais do ensino fundamental: tecendo fios do ensinar e do aprender. Belo Horizonte: Autêntica, 2009.

NACARATO, A. M; PAIVA, M. A. V. A formação do professor que ensina matemática: estudos e perspectivas a partir das investigações realizadas pelos pesquisadores do GT7 da SBEM. In: NACARATO, A. M.; PAIVA, M. A. V. (Org.). A formação do professor que ensina matemática: perspectivas e pesquisas. Belo Horizonte: Autêntica, 2008. p. 7-26.

PIMENTA, S. G. Professor reflexivo: construindo uma crítica. In: PIMENTA, S. G.; GHDIN, E. (Org.). Professor reflexivo no Brasil: gênese e crítica de um conceito. São Paulo: Cortez, 2008. p. 17-52.

PONTE, J. P. Concepções dos professores de matemática e processos de formação. In: Educação matemática: temas de investigação. Lisboa: Instituto de Inovação Educacional, 1992. p. 185-239.

SCHÖN, D. Educando o profissional reflexivo. Porto Alegre: Artmed, 2000.
TARDIF, M. Saberes docentes e formação profissional. 9. ed. Petrópolis: Vozes, 2008.

ZAIDAN, S. Educação matemática: ampliação e reconstrução do conhecimento escolar. In: DALBEN, A. I. L. F.; GOMES, M. F. C. (Org.). Formação continuada de docentes da Educação Básica: construindo parcerias (LASEB). Belo Horizonte: Autêntica, 2009. p. 53-69.

ZAIDAN, S; SOUTO, K. C. N. Ampliando as relações entre teoria e prática na formação docente: a disciplina ACPP como eixo integrador da proposta do LASEB. In: DALBEN, A. I. L. F.; GOMES, M. F. C. (Org.). Formação continuada de docentes da Educação Básica: construindo parcerias (LASEB). Belo Horizonte: Autêntica, 2009. p. 211-222.

\section{Notas}

1 Para compor essas turmas, foram oferecidas 200 vagas para educadores infantis e professores do ensino fundamental e médio da RME, assim reservadas: até $10 \%$ aos professores com deficiência; até $40 \%$ para os professores que se autodeclararam negros; e 50\% para a categoria OUTRO. Seguindo esses critérios, as vagas foram direcionadas aos professores que atuassem na sala de aula ou coordenação pedagógica, fossem estáveis na Rede Municipal de Belo Horizonte, com pelo menos cinco anos de efetivo exercício do magistério, e não estivessem ocupando cargos em comissão; que tivessem concluído curso de graduação em licenciatura plena em qualquer área do conhecimento ou em Pedagogia e não tivessem concluído ou estivessem cursando especialização lato sensu ou stricto sensu (GOMES et al., 2009).

2 O núcleo comum foi estruturado em torno de diferentes modalidades de atividades integradas, como seminários, oficinas, grupos de reflexão sobre a prática docente, oferecidas de maneira coletiva para as turmas e não por área de concentração.

3 Neste trabalho, a história oral é concebida, conforme Garnica (2007), como um método qualitativo de pesquisa que também pode ser utilizado como um recurso para pesquisas que não têm, especificamente, uma "questão histórica" a ser investigada.

4 Nesse período, foram desenvolvidas as seguintes disciplinas: A Educação Matemática; Fundamentos do Ensino de Matemática I - Números de Contagem: surgimento, organização e significados; Fundamentos do Ensino de Matemática II - Números de Medidas: surgimento, organização e significados; Educação, Sociedade e Cultura.

5 Algumas das professoras, quando consultadas quanto ao uso de seus nomes reais, expressaram o desejo de que eles fossem mencionados; outras disseram ser isso indiferente para elas, deixando para nós a decisão. Em concordância com essas posições, decidimos nos referir a todas as participantes por seus nomes reais.

6 As entrevistas foram realizadas no ano de 2011.

7 Foram suprimidos do texto da transcrição alguns registros repetidos ou de cunho pessoal ou político, que as depoentes solicitaram que não fossem divulgados. Esses registros, embora não tenham sido textualizados, contribuíram para a pesquisa na compreensão das narrativas.

8 Informações sobre o grupo e seus trabalhos estão disponíveis em: $<$ www.ghoem.com>.

9 A professora assim se referiu aos estudantes com deficiências comprovadas através de laudo médico, bem como aos estudantes com necessidades diferenciadas de aprendizagem.

${ }^{10}$ A autora encontrou, em média, 36 a 72 horas destinadas ao desenvolvimento de disciplinas voltadas para os conhecimentos matemáticos, o que corresponde a cerca de $4 \%$ a $5 \%$ da carga horária total do curso.

${ }^{11}$ Usamos o termo representações conforme o sentido de representação social proposto por Jodelet (2001, p. 36): "uma forma de conhecimento, socialmente elaborada e partilhada, tendo uma visão prática e concorrendo para a construção de uma realidade comum a um conjunto social".

Artigo recebido em setembro 2013 Aprovado em dezembro 2013. 